VNU Journal of Science: Legal Studies

Journal homepage: https://js.vnu.edu.vn/LS

Original Article

\title{
The Hardship Clause as a Solution for the Risk of Frustrated Contract in Viet Nam
}

\author{
Tran Trung Nguyen* \\ HUMG, No. 18 Vien Street, Bac Tu Liem District, Ha Noi, Viet Nam \\ Received 04 February 2021 \\ Revised 18 March 2021; Accepted 24 June 2021
}

\begin{abstract}
This article has two aims. Firstly, it critically analyses all major legal aspects of the Viet Nam's hardship clause that can be used in a contract to protect contractual parties. Secondly, it derives the possible adjustment or interpretation toward the Vietnam's hardship clause to improve its applicability and practicality while giving the optimal approach toward minimizing the risk of a contractual party through applying the hardship clause. European States and international private laws present a comprehensive evolution of its hardship clauses through numerous cases spreading across major historical events. It is hoped that the best practices can be adopted for any party wanting to establish a long-term trade in Viet Nam so such party can take the most relevant option from the Vietnam's legal system.
\end{abstract}

Keywords: Hardship clause, Viet Nam law, frustration, change of circumstances.

\section{Introduction}

\subsection{Background}

Unforeseeable circumstances that drastically changed the contractual basis is a major issue for contractual parties, especially in international trade. Such issue affects the paradigm of pacta sunt servanda [1] known as the sanctity of a contract which puts the burden of such change of circumstances on the

\footnotetext{
$\bar{*}$ Corresponding author.

E-mail address: nguyentran96vn@gmail.com

https://doi.org/10.25073/2588-1167/vnuls.4344
}

contractual party that it falls onto. However, since the old Roman days, the principle of rebus sic stantibus [1] stipulates that the contractual obligations can be modified in the event of an unforeseeable and extraordinary change of circumstances making the contractual obligations become onerous. In the $21^{\text {st }}$ century, the hardship clause and its similar expression such as frustration, change of circumstances, changement de circonstances, Wegfall der Geschäftsgrundlage, Théorie de l'imprévision are used in a number of private law systems, in which the concept of hardship is the most common and widely accepted as a customary law [2]. 
The appearance of the hardship clause in the Vietnam's law started with the change of basic circumstances which was included in the Vietnam's Law on Insurance Business in 2000 [3] but at that time, it was strictly for the insurance business. During that time, the hardship clause was still a new ground and only had been added recently to the Vietnam's Civil Code in 2015 [4] after being carefully adapted from other modern legal doctrine [5]. In difference with the common law system, such as in the UK for which relied on precedent legal cases, Vietnamese legal framework bases principally on treaty law and written law while the case law is only applicable when the issue is not addressed in the civil law nor agreed by the parties, common fairness, justice, nor the analogy of law [6], so the description of such criteria shall mainly be interpreted from the written law because there is currently no case law related to the hardship clause stipulated in the Article 420 of the Vietnam's Civil Code 2015 yet [7].

\subsection{Purpose}

This article seeks to provide an original research through a critical analysis of the approach of Viet Nam toward the implementation of the hardship clause with regards to the view of other modern legal doctrines. Due to the young nature of the Vietnamese legal doctrine with respect to the hardship clause with no legal supplement document nor any related case law, this research will attempt to derive some suggestions to improve the application of hardship clause in Viet Nam by using the sociolegal research methodology within the context of the related historical events and relevant cases with the comparative method to analyse of the compatibility and applicability of Vietnamese's hardship clause in comparison with United Kingdom, France, German, and international private laws.

\section{Defining the Hardship}

\subsection{Common Criteria of the Hardship Clauses}

In many Central European states, along with the international private law, the hardship clauses share a major resemblance toward each other with four common conditions of defining the change of basic circumstances, which are [8]:

i) There is a fundamental change in contractual equilibrium

ii) The change of circumstances has no connection to any contractual party.

iii) Circumstances is not foreseeable at the conclusion of the contract

iv) Parties would not conclude the contract or conclude with different content if the circumstances were known before the conclusion of the contract.

In this article, the term "circumstances" needs to be understood as a fact, condition or event that is connected with, relevant to or make a situation the way it is [1].

The term "basic circumstances" need to be understood, within the context of a contract, are the circumstances that is vital to the operation of the contract. The basic circumstances are defined on the facts at the conclusion of the contract, regardless of the consent of the contractual parties and it must be legal in accordance with the state's law. The basic circumstance of a civil contract has 2 types: economic and non-economic. An economic basic circumstance is generally referred as a circumstance that is directly related to the economic value such as pricing while the noneconomic type is generally referred as a circumstance that is directly related to the contractual operation and not affected by any aspect of the pricing issues.

The term "changes in basic circumstances" can be understood equally as "the change of circumstances is basic" and it represents the 
same state of the contract with regards to the term "fundamental change in the equilibrium of the contract". Due to different types of the basic circumstances of the contract, each criterion will have different interpretation in determining the threshold of a change of basic circumstances capable of inducing a hardship. In order to fully understand the relation between each criterion with different types of the change of basic circumstances, chapter 2 will critically assess each criterion of the hardship clause and its threshold for each different type of change of basic circumstances under the view of different states and an international private law.

\subsection{There is a Fundamental Change in the Contractual Equilibrium}

In the Vietnam's Civil Code 2015, the change of circumstances which causes a fundamental change in contractual equilibrium is legally acknowledged only when satisfying all 5 requirements as follow:

i) The circumstances change due to objective reasons occurred after the conclusion of the contract

ii) At the time of concluding the contract, the parties could not foresee a change in circumstances

iii) The circumstances change such greatly that if the parties know in advance, the contract has not been concluded or are concluded, but with completely different content

iv) The continuation of the contract without the change in the contract would cause serious damage to one party

v) The party having interests adversely affected has adopted all the necessary measures in its ability, in accordance with the nature of the contract, cannot prevent or minimize the extent of effect

These requirements are stipulated in Article 420.1 of the Vietnam Civil Code 2015 with the significant threshold of the alteration of contractual equilibrium is based on its adverse impact endured by a disadvantaged party under
2 areas: how radical did the contractual obligations changed and the continuation of the original contractual obligations [9]. Based on the phrase "serious damage to one party", it can be seen that economic fluctuation affects the value of performing the original obligations can also be qualified for the change of basic circumstances as shown in [9]. But unlike the view of the French legal doctrine, the contractual party is obliged to adopt all necessary measures within its ability, in accordance with the nature of the contract, yet can't minimize or prevent the extent of the adverse effect before being able to claim that the equilibrium of the contract is altered because as stated in the article 420.1, "the change of circumstances shall be deemed basic when it meets all following conditions: ... The party having interests adversely affected has adopted all the necessary measures in its ability, in accordance with the nature of the contract, cannot prevent or minimize the extent of effect" so the obligation of adopting all necessary prevention measures becomes an extra requirement for the legal recognition of an alteration of contractual equilibrium [9].

In case of a corporation becomes a disadvantaged party in a contract that doesn't specify the hardship clause with specific responses, then the phrase "adopted all the necessary measures in its ability, in accordance with the nature of the contract" will force the big corporations to exercise an enormous amount of resource to negate the hardship before being able to invoke the hardship clause because the ability of a big corporation is massive while adopting all necessary measures may cost the disadvantaged party more than what the contract can bring originally. However, under the freedom of the contract, as stated in article 11 of the Law on Commercial 2005 [10], parties are free to reach an agreement within the allowance of the law, fine traditions, custom, etc so by including the specific hardship clause that states the limit of the response of parties for the hardship event, 
the phrase "in accordance with the nature of the contract" will allow parties to only need to exercise all necessary measures in its ability up to the desired limit as stated in the contract before invoking article $420(\mathrm{dd})$ of the Vietnam Civil Code 2015.

\subsection{The Change of Circumstances has No Connection to Any Contractual Party}

Within the hardship clause in the Vietnam's Civil Code 2015, Viet Nam doesn't directly stipulate the second common criterion of the hardship as shown in the beginning of part II but the result of such common criteria is achieved through inducing an obligation of exercising all necessary measures within the reasonable limitation of the disadvantaged party, in accordance with the nature of the contract, to prevent or minimise the adverse effect whether the act is successful or not [9].

The first result is the prevention of abusing the hardship clause which has happened since 1926 with the case Hirji Mulji v Cheong Yue Steamship Co where it was affirmed that "charterer was aware of the included risk of the contract yet still carried on working then claimed that the contract is frustrated due to the risk even though the risk was acknowledged by him as it was within the reasonable expected risk when taking on that contract" [11]. Thus, the connection between the change of circumstances and contractual parties was stipulated as "... whatever the consequences of the frustration may be upon the conduct of the parties, its legal effect does not depend on their intention or their opinions, or even knowledge, as to the event, which has brought this about..." [11]. In the first result, even if the disadvantaged party have knowledge of the possible outcome before the appearance or the sign of the severe adverse impact or connection to the incident, they will be forced to try all possible approaches to negate the impact of frustrated circumstances which negates the possible benefit from abusing the hardship doctrine. In combination with the principle of good faith [9], exercising any possible approach that may cause, increase, or support any change of circumstances which may impose adverse impact into disadvantaged party is a violation of this criterion.

In addition, as contractual parties usually stipulate the hardship clause in the contract, especially the long term contract or any contract with certain type of inherited risk, the Article 420(dd) of the Vietnam's Civil Code 2015 will promote the detailed stipulation of the hardship clause in the contract in order to not waste their resource on any possible unknown interference in the future which will likely reduce the change of requesting a judicial injunction from the court. However, this will also impose a burden into disadvantaged party for exercising their best reasonable effort to maintain the contract but it can be overcame by stipulating the limit of possible responses from the view of disadvantaged party in the contract when an event of default appears.

As the result of the second common criterion stated in part 2.1.1. of this article is achieved through a different wording in Article 420 of the Vietnam Civil Code 2015, there may be an unknown weakness resulted from the different approach of the Vietnam's hardship clause in comparison to other legal doctrine but the Vietnam's hardship clause has to be used in parallel with the article 5 and 6 of the Vietnam Civil Code 2015 [9] for which the analogy of law and common practice need to be respected as well, so any possible outcome related to the second common criterion will certainly be covered by the combination of Article 5,6, and 420 of the Vietnam Civil Code 2015. Even if an unprecedented hardship case happens, it will certainly be selected to become a legal precedent, according to the Resolution on Process for Selecting, Publishing and Applying Precedents to be applied when deciding later cases [12]. 


\subsection{Circumstances are not Foreseeable at the Conclusion of the Contract}

The concept of unforeseeable circumstances after the conclusion of the contract is a universal criterion of assessing a claim of hardship that is approved by a number of national legal frameworks and international private laws [8]. For this section, we refer to the conclusion of the contract as the moment at which the acceptance of an offer becomes operatives, according to the CISG [13]. The phrase "reasonable circumstances" is to be understood, with regards to the nature of the contract, as any possible change of circumstances caused by inherited risk from the nature of the contract, regardless of the knowledge of contractual parties.

The Vietnam's Civil Code 2015 directly stipulate that criteria in section 1(b) of Article 420: "At the time of concluding the contract, the parties could not foresee a change in circumstances" which determines that the hardship can only happen beyond any reasonable calculation within and the phrase "At the time of concluding the contract" determines that the cause of the change of circumstances or the risk can only happen after the conclusion of the contract.

In case of the sign of the cause of the change of circumstances happens before the conclusion of the contract but the cause of the change of circumstances happen after the conclusion of the contract, unless the sign directly hints toward the existence of the cause of the change of circumstances or else it will not be sufficient to claim that the change of circumstances is foreseeable.

Thus, setting the limit of reasonable expectation in a contract can be expressed as stipulating the basic ground of the contractual operation so any contractual deviation against basic contractual circumstances that exist on a ground not stipulated in the contract may be qualified for the unforeseeable change of circumstances criterion.

\subsection{An Example of the 2.4 Criterion in Practice}

For a realistic example of this criterion, we will look at the case of the COVID-19 incident.

In the early stage of the Covid-19 pandemic, WHO recommended nations to keep their border open and the CDC didn't recommend wearing masks for people who were well at the $31^{\text {st }}$ of January 2020 [14] then later on $1^{\text {st }}$ of March, Viet Nam imposed a compulsory 14 days quarantine for everyone entering Viet Nam border [15] so, if a contract was signed during the first week after the $31^{\text {st }}$ of January for an operation only in Viet Nam then the sign of the border restriction was already presented before and based on the isolation of Wuhan in China and Lombardy in Italy [16], it can be argued that either a global pandemic was a next possible outcome at that time or the idea of virus pandemic leading to a major hardship for international contract was a hoax when it was not treated as a serious issue at that time by many nations and WHO. However, between $31^{\text {st }}$ of January and $1^{\text {st }}$ of March, the border control resulted from such sign is beyond any reasonable limit that parties can foresee because the WHO recommendation, other states legal responses toward the COVID-19 has no legal effect in Viet Nam because the court will only take into account the legal authority of the place hosting the operation of the contract.

So, the change of basic circumstances known as the border restriction can only be within a reasonable expectation when a contract is signed between $31^{\text {st }}$ of January and the $1^{\text {st }}$ of March if there is a legal acknowledgement from the Vietnamese government regarding the possible pandemic in Viet Nam resulted from 
the COVID-19 before the conclusion of the contract.

\subsection{Parties Would not Conclude the Contract or Conclude With Different Content if the Circumstances Were Known Before the Conclusion of the Contract}

According to the Article 420 of the Vietnam's Civil Code 2015, it is stipulated that the parties would not conclude or conclude the contract with a completely different content if they have foreseen the change of circumstances in advance [9] which set out a requirement of a completely different change of contractual content for the qualification of a hardship. The meaning of the word "completely different" can be understood that, within the context of this regulation, the change is severe and distinctive in a way that carrying out the original obligation as stipulated in the contract will result in severe losses for disadvantaged parties whether such loss is financial or not. However, as entering the contract equal to accept a certain degree of inherited risk from the contract, so if the contractual operation becomes radically deviated but within the risk inherited from the contract then the change of circumstances will not be sufficient to make the operation go under a different contract.

As Viet Nam only have the Article 420 of its Civil Code for dealing with the case of hardship with a lack of relevant case in Viet Nam because the article 420 was ratified in 2015. However, as a member state of the New York Convention [17], Viet Nam, with regards to the case of hardship in any international contract is expected to reasonably satisfy the basic criteria of the hardship clause in international private law and other developed state's private laws to be consistent with the general view. Thus, we can consult the view of other developed states about the general expectation of the threshold of a hardship resulted from either an economic fluctuation or a non-economic situation.
For a hardship resulted from a noneconomic fluctuation, a suitable example is looking at the frustrated contract clause of the United Kingdom for which doesn't accept the alteration of the contractual equilibrium in term of commercial benefits as established in the case of Davis Contractor 1956 [8] where the cause of the alteration of contractual equilibrium criteria was deemed not satisfied even though inadequate supplies lead to a 22 months of labour instead of 8 months [8] after considering 4 background criteria which were the express words of the contract, its nature and subject-matter, the surrounding circumstances in which it was made, and the events as they turned out afterwards [8].

After consulting a number of cases of hardship across the globe due to the lack of hardship case in Viet Nam, Vietnamese legal researchers concluded that the economic threshold as expressed by "completely different" is, in general, and not as a fixed threshold for any other case, at roughly either $50 \%$ or $70 \%$ for the interpretation of the Art 420 (1(c)) of the Vietnam's Civil Code and following the same legal framework of couple developed states with the change of balance in contractual obligations is considered as a core criterion in estimating the change of basic circumstances in a hardship by a number of courts and arbitration [5].

In short, this criterion can be understood as a general threshold for the change of basic circumstances under the view of the disadvantaged party, whether such change is an economic fluctuation or not.

\subsection{An Example of the 2.6 Criterion}

The situation of this criterion can be understood under the context of the related case example stated in the UNIDROIT Principles of Commercial Contracts 2016 [18] where carrying on with the original obligations will be onerous for party A because the competitiveness of A's is significantly reduced due to the general access to a cheaper 
alternative source of goods from its competitors and not only that, A can't be reasonably aware of the merge of the north German and the West by the time of the conclusion of the contract so in this specific case, the situation of A satisfies the criterion of disrupted contractual basis.

\section{Application of the Hardship Clause}

\subsection{Party's Obligations Before the Completion of Negotiating and Adjusting the Contractual Obligations in a Frustrated Contract}

The term "a reasonable period of time" or "reasonable time" needs to be understood as a period of time for which is determined in the hardship clause of the contract for each possible event that may happen. In general, a contract will clearly state the communication channel between parties and the corresponding period of time to conduct a pre-arranged act in each stipulated circumstance. In case of a contract not stating the reasonable response time in the presence of a hardship, then the general response time of other corporation for that issue shall be used as a measure with an allowance of deviation. For example, in the Section: Event of Default of a contract which uses the Vietnam's Civil Code 2015, if the contract states that parties need to respond within 3 days of receiving the hardship claim then after 72 hours of receiving such claim, the received party will automatically be labelled as not responding within the reasonable amount of time and the party which claim the hardship can invoke Article 420.2 and 420.3 of the Vietnam's Civil Code 2015 to request a judicial decision of the court.

The Vietnamese law directly stipulate the requirement of carrying on with the original contractual obligations during the negotiating the amendments, termination, and courthandling the case in Article 420(4) of the Vietnam's Civil Code 2015 [9]. The act of carrying on with the original contractual obligations is nothing but a standard procedure as seen in many developed state's civil code and the international private law [19]. It should be noted that in a case of hardship resulted from a non-economic circumstances, the UK Law Reform (Frustrated Contract) Act 1943 states that all continuous obligations along with the future obligations are discharged immediately at the point of frustration [20]. However, as the UK doesn't accept economic fluctuation as a change of basic circumstances so an immediate termination of the contract is acceptable as the contractual operation is already severely hindered at the point of frustration. Parties can adapt this concept into their contract under the Event of Default Section for which any change of basic circumstances that is non-economic can immediately discharge all continuous obligations along with any future obligation.

In case of non-specifying the responses regarding any possible hardship event, the amount of reasonable time under the Viet Nam hardship clause need to be taken account with respect to the related circumstances and the nature of the contract itself under the view of the disadvantaged party. The party invoking the hardship clause by the self-determined reasonable amount of time is responsible for their choice of such time if such choice is deemed inadequate by the court or the arbitration.

\subsection{The Result of Invoking the Hardship Clause}

Upon facing the hardship resulting in an excessively onerous obligation to a party, any contractual party has 2 main choices to amend the contractual obligations by either renegotiating under the mutual agreement of both sides or terminating the frustrated contract. These options are stipulated in numerous domestic and international private laws [21]. Requesting for the renegotiation of the contractual obligation is generally be in the higher priority before requesting for the adaptation of the jurisdiction of the court when the contract is frustrated by an economic fluctuation because a contract frustrated by an 
economic change can still be physically carried out even if the continuation of the contract will impose a serious economic loss for the disadvantaged party. In a case of a contract frustrated by a non-economic frustration, then it is likely that the contractual operation is obstructed so carrying on with the obligations is impossible in such case. In such situation, restoring the contractual equilibrium is generally beyond the capability of the parties so a termination is generally the best approach.

Article 420 of the Vietnam's Civil Code 2015 states that upon the failure of amending the contractual obligations under the agreement of all parties within a reasonable period of time, any of the parties may request a court to either terminate the contract at a specific time or amend the contract to balance the lawful rights and interests of the parties. However, the amendment of the contract under the jurisdiction of the court can only happen when the termination of the contract would cause greater damage than the cost to perform the modified contract [9]. This requirement is absent in the legal process of invoking the hardship clause in many domestic and international private laws [22]. This clause ensures that the damage from any act of changing the contract will be minimal while ensuring the contractual equilibrium to the best possible way.

Upon the invocation of hardship clause in Article 420 of the Vietnam's Civil Code 2015, the amendment of the contract and the termination of the contract stipulated in Article 421 and Article 422 of the Vietnam's Civil Code 2015 respectively will be invoked as prescribed in Article 420 of the Vietnam's Civil Code 2015. This is believed to avoid the possible judicial overreach from the court when modifying the contractual obligations but this also imposes a burden to the court in applying the hardship clause as determining the damage in the case of contractual termination, and the cost of performing the modified contract is extremely difficult as each case is unique when looking at under the view of the disadvantaged party [5].

\subsection{Arbitration Court in the Vietnam's Hardship Clause}

Internationally, the words "court" is generally perceived as the domestic court in the respective state or the arbitration court with the inclusion of the arbitration court as shown in the case No. 7365/FMS, and No. 9994 of the court ICC International Court of Arbitration 9994 [23]. As the word court is also used without any further explanation in the Vietnam's Civil Code 2015 but under Article 4.4 of the Vietnam's Civil Code 2015 that put the international agreement in the higher priority than the Viet Nam provisions indicating the same matter [9], the word "court" shall be understood as any court with the inclusion of the arbitration court. The Article 5 of the Law on Commercial Arbitration 2010 allows for settling the dispute under arbitration if parties agreed so while its Article 6 allows the court to refuse to accept any lawsuit that reached an arbitration agreement if the arbitration agreement is still effective at such time [24].

Furthermore, as Viet Nam has been a member state of the New York Convention since 1995 which recognise and enforce any arbitral awards made in the territories of other Contracting State [25] then the interpretation of the hardship clause from the Vietnam's Civil Code should be aligned with the international concept of hardship based on the declaration of Viet Nam on the New York Convention [26] and in order to show a good faith toward developed states for maintaining a good relationship.

Thus, Article 420 of the Vietnam's Civil Code 2015 is bound to accept all judicial decision of any arbitration court, whether it is domestic or international which gives contractual parties the flexibility of applying the hardship clause under different type of jurisdiction. 


\section{Improving the Hardship Clause for VietNam}

\subsection{Present and Future Challenges with Regards to the Application of the Hardship Clause in Viet Nam}

Through previous chapters, it is shown that Vietnam's hardship clause is highly compatible with the legal hardship clause of developed states and the international private commercial law such as the UNIDROIT Principles of International Commercial Contracts. However, unlike United Kingdom, France, and Germany which has a rich background of case law about hardship to rely on as a mean of legal supplement and citation, the poor background of the hardship clause in Viet Nam [6,7] with the lack of legal documents for explaining the terms and its application which is opposite against the well documented UNIDROIT Principles of International Commercial Contract 2016. Furthermore, the digital infrastructure of legal documents of a developing state like Viet Nam is not as efficient as other developed state's digital infrastructures.

A number of small and medium-size companies in Viet Nam are incapable of approaching basic supports and legal consultancy from the government so their ability to apply new laws in their contract is still poor [27]. Due to the small scale of operation, small-size companies, especially family-owned small companies generally have to terminate their contract upon facing hardship as the cost for amending the contract, arising extra fees are too costly for them. As a result, Vietnamese small and medium-size corporations don't have the same accessibility to all possible interpretation of the hardship clause as the big corporation of which limits the capability of applying the hardship clause into their contract either before the conclusion of the contract or during the operating time of the contract.

Thus, despite the high compatibility between the Vietnam's hardship clause with the hardship clause of a number of developed states and the international private law such as the
UNIDROIT Principles of International Commercial Contracts 2016, the applicability of the Vietnamese hardship clause is still at an undesirable level due to the issue stated in the previous paragraph.

4.2. Proposal for the Application and Improvement of the Hardship Clause and its Effectiveness in the Long Run

The hardship clause of the Vietnam's Civil Code 2015 is designed to maintain the paradigm pacta sunt servanda as much as possible under changes of basic circumstances in order to maintain a stable economy in a time of hardship, which is represented by the COVID-19 pandemic in 2020 as an example by maintaining as many contracts as possible. Thus, my proposal for the amendment of the hardship clause shall be developed to elevate and support the aim of the hardship clause as shown above.

Due to the low applicability of the hardship clause shown in section 4.1, this section will propose a couple of improvement for the applicability of the hardship.

i) For the lack of legal guidance about the application of the hardship clause, a legal guiding document is needed to define certain terms and situations with corresponding examples. This legal guidance may be presented under type NĐ-CP from the government and follow the structure of the UNIDROIT Principles of International Commercial Contracts 2016 due to two reasons: Firstly, the NĐ-CP document is used as a legal guideline for any law and it has the legal binding effect nation-wide [28]. It also has a restricted scope of act, so it takes less time to be amended or replaced as it doesn't need the approval of the National Assembly. Secondly, the UNIDROIT Principles of International Commercial Contracts 2016 Article 6.2.2 and 6.2.3 have detailed comments to explain each sub-clause in the hardship clause with corresponding illustrations which will allow readers to understand the clause properly in the 
real context so using the structure of UNIDROIT Principles of International Commercial Contracts 2016 for the NĐ-CP will greatly enhance the applicability of the hardship clause for small and medium-size companies. Due to two reasons above, this change is highly practical even in a distant future and when there is a change in understanding the hardship clause then the guide can always be amended in the future. The guidance with regards to the clause 420(dd) of the Vietnam's Civil Code 2015 will protect parties from misunderstanding clause 420.1(dd) of the Vietnam's Civil Code 2015 as shown in the chapter two part two of this article.

ii) As the hardship clause is generally relevant to long term contract [18], a party with a valuable long term contract should include the hardship clause in the contract with certain modifications as follow if parties decide to use the Vietnamese Law for the contract:

Firstly, as invoking the hardship clause will let parties enter a renegotiation round so a reasonable limit of the response time and renegotiation period need to be stated in the contract to protect the disadvantaged party from receiving major adverse impact from exercising the onerous obligation during the excessively long period of renegotiation.

Secondly, as the clause dd of Article 420 in the Vietnam's Civil Code 2015 imposes a burden on the disadvantaged party then parties can set the limit of all necessary measures in the contract to protect the disadvantaged party as follow:

As the clause dd of Article 420 uses the phrase "all the necessary measures in its ability, in accordance with the nature of the contract, cannot prevent or minimize the extent of effect" then parties can define the limit of the necessary measures that disadvantaged party can exercise before being able to claim that it has already adopted all necessary measures in its ability because the phrase "in accordance with the nature of the contract" so if the limit of the necessary measures is stipulated in the contract then the disadvantaged party only need to exercise all those measures stated in the contract even if the disadvantaged party is capable of exercising more costly measures.

iii) In order to implement the legal guidance under the Decree NĐ-CP following the preset UNIDROIT Principles of International Commercial Contracts 2016 as stated in the first proposal with mentioned explanation in previous chapters, as follow:

+ Article 1. Scope

This Decree elaborates formulation, approval, announcement, implementation, assessment and adjustment of detailed planning specified in Clause 1 Article 420 of the Civil Code 2015.

+ Article X. Contents of the change of basic circumstances

At the time of concluding the contract, the parties could not foresee a change in circumstances

According to Clause 1.(a) of Article 420, the change of circumstances exists due to a cause happened beyond any reasonable calculations of contractual parties with regards to the nature of the contract for which reasonable calculations are based on the moment of concluding the contract. When concluding the contract, parties automatically accept a certain amount of inherited risk related to the nature of the contract, regardless of the consent of parties for which any change of circumstances resulted from the inherited risk shall be deemed foreseeable.

Illustration (taken from UNIDROIT Principles of International Commercial Contracts 2016): A agrees to supply B with crude oil from country $\mathrm{X}$ at a fixed price for the next five years, notwithstanding the acute political tensions in the region. Two years after the conclusion of the contract, a war erupts between contending factions in neighbouring countries. The war results in a world energy crisis and oil prices increase drastically. A is not entitled to invoke hardship because such a 
rise in the price of crude oil was not unforeseeable.

iv) Promoting the use of Arbitration Court instead of the traditional People's Court in Viet Nam with regards to the hardship clause to improve the applicability of the hardship clause. Arbitration Court has 4 main advantages over the People's Court as follow:

+ The procedure of the Arbitration Court is simpler than the People's Court in Viet Nam and has less requirement so parties can save time and money.

+ Parties can selection specific arbitrators who have experience and credit regarding the related case.

+ The entire procedure of the Arbitration Court is confidential while the procedure of the People's Courts is public and even if there is a trade secret or professional secret involved, the Court may conduct the trial behind closed door [29], which does not fully guarantee the confidentiality. Confidentiality will protect the credibility of parties, especially parties on the stock market where the economic rating of corporations is highly sensitive against any related information.

Under the New York Convention and the Law on Commercial Arbitration [30], the decision of the Arbitration Court has the same judicial power as the decision from the traditional court such as the People's Court of Viet Nam and it is enforceable even in foreign state under the New York Convention. Thus, the Arbitration Court is a good alternative option for parties that prefer modifying the contract over terminating it due to the hardship.

+ With regards to the small size company, their contracts are generally low funding so the hardship clause isn't as applicable as the force majeure clause to them because the extra fees arising from the hardship is generally more costly than the goods so abandoning is the best option for them. For such reason, the application of the hardship clause is generally not effective for small companies with short term contract. A support in term of funding and lowering the interest rate in the bank is a better resolution which is already created under the government directive [31] is generally better than trying to apply the hardship clause for a contract that is short term and low cost.

\section{Conclusion}

After comparing the hardship clause between Vietnamese law against developed states law and the international private law such as UNIDROIT Principle on International Commercial Contract, it is shown that the Vietnam's hardship clause is compatible to other modern legal doctrines and even the international private law despite having a different approach in the hardship clause. The Vietnam's hardship clause has followed the hardship clause of France and UNIDROIT PICC with the inclusion of the economic fluctuation as a change of basic circumstances which is different against the UK's approach which does not accept economic fluctuation as change of basic circumstances. Despite the similarity in accepting the economic fluctuation as a change of basic circumstances, the Vietnam's Civil Code approaches the definition of the hardship event in a different manner. This difference makes the requirement for invoking the hardship clause much tighter in comparison to the French hardship clause and it can be seen as a mixture of the English and French hardship clause. However, due to certain issues shown in part 4 of this article, the applicability of the hardship clause is still behind in comparison with developed states and international private law such as United Kingdom, Germany, France, and UNIDROIT Principle on International Commercial Contract not because of the law itself, but the infrastructure to support such law so a comprehensive suggestion is needed to improve the applicability of the hardship clause under the view of the contractual party and the lawmaker. With proper improvement, the 
applicability of the hardship clause in Viet Nam will be improved significantly and corporations can utilise the hardship clause for their contract efficiently, especially in the age of globalisation.

\section{References}

[1] See the Efinition of Pacta Sunt Servanda in the Oxford Dictionary at https://www.oxfordreference.com/view/10.1093/o i/authority.20110803100300496, (accessed on 09/07/2020).

[2] B. Oglindă, The Theory of Imprevision in the Context of the Economic Crisis and the New Romanian Civil Code (NCC) (2012) 1 Persp Bus LJ 230 Section 1(A).

[3] Law on Insurance Business No. 24/2000/QH10 2000, article 20(1); D. Dai, Scientific Commentary: New Point in the Vietnam's Civil Code 2015 (3rd edn, Hong Duc Publisher 2020) Section 345 and the Author of This Book is a Member of the Committee Revising and Proposing the Draft of the Vietnam's Civil Code (officially known as Law No. 91/2015/QH13) and the Art 420 mentioned in Particular for the National Assembly of Vietnam.

[4] Vietnam's Civil Code No. 91/2015/QH13 2015, Art 420.

[5] N. M. Hang and T. T. G. Thu, Proposing the Interpretation and Application of Article 420 Civil Code 2015 Regarding the Implementation of The Contract when the Circumstances Change Fundamentally (26/10/2017) Journal of International Economics and Management No.86; Đ. V. Đai, Scientific Commentary: New Point in the Vietnam's Civil Code 2015(3rd edn, Hồng Đức Publisher 2020) Section 345.

[6] D. V. Dai, Scientific Commentary: New Point in the Vietnam's Civil Code 2015 (3rd edn, Hồng Đức Publisher 2020) Section 30; Vietnam's Civil Code No. 91/2015/QH13 2015 Section 6; See Article 1 and 2 of the Resolution on Process for Selecting, Publishing and Applying Precedents No. 04/2019/NQ-HĐTP.

[7] See the Collection of Case Law in Viet Nam With no Case Law Related to Hardship in https://thuvienphapluat.vn/tintuc/vn/an-le/, (accessed on 09/07/2020).
[8] See Davis Contractor LTD. v Fareham UDC [1956] A.C.696 Where it Was Held That "...frustration occurs whenever the law recognizes that without default of either party a contractual obligation has become incapable of being performed because the circumstances in which performance is called for would render it a thing radically different from that which was undertaken by the contract. Non haec in foedera veni. It was not this that I promised to do..."; Vietnam's Civil Code No. 91/2015/QH13 2015, Art 420; French Civil Code 2016 Art 1195; Germany Civil Code 2013 Section 313; UNIDROIT Principles of International Commercial Contracts 2016 Art 6.2.2.

[9] Vietnam's Civil Code No. 91/2015/QH13 2015, Article 420 (c, d).

[10] Law on Commercial No.36/2005/QH11 2005, Article 11.

[11] Hirji Mulji and Others v Cheong Yue Steamship Co, Ltd [1926] AC 497 page 500.

[12] Resolution on Process for Selecting, Publishing and Applying Precedents No. 04/2019/NQ-HDTP, Article 1 and 2.

[13] United Nations Convention on Contracts for the International Sale of Goods 2010, Article 23.

[14] See the Press Briefing Transcript for CDC Media Telebriefing: Update on 2019 Novel Coronavirus(2019-nCoV) Where the CDC didn't Recommend Wearing Mask for Healthy People https://www.cdc.gov/media/releases/2020/t01312019-novel-coronavirus.html, (accessed on 4/7/2020)

[15] Official Dispatch No. 1440/CV-BCĐ 2020.

[16] China Coronavirus: Lockdown Measures Rise Across Hubei Province, British Broadcasting Corporation News (23/1/2020) https://www.bbc.com/news/world-asia-china51217455, (accessed on 4/7/2020).

[17] The Convention on the Recognition and Enforcement of Foreign Arbitral Awards 1958.

[18] UNIDROIT Principles of International Commercial Contracts 2016 Art 6.2.2(2(1)); Case SG 126/90 [1990] Schiedsgericht Berlin.

[19] German Civil Code 2013, Section 313(3); French Civil Code 2016, Art 1195; UNIDROIT Principles of International Commercial Contracts 2016, Article 6.2.3(4).

[20] Law Reform (Frustrated Contracts) Act 1943, Section 1(1). 
[21] Maritime National Fish Ltd v Ocean Trawlers Ltd [1935] All ER Rep 86; French Civil Code 2016 Art 1195; Germany Civil Code 2013 Section 313; ICC Force Majeure and Hardship Clause 2020; UNIDROIT Principles of International Commercial Contracts 2016 Art 6.2.2.

[22] See the Absence of Any Similar Clause Like the Article 420(c, d) of the Vietnam's Civil Code No. 91/2015/QH13 2015 in Other Regulations Stated in [21].

[23] Ministry of Defense and Support for the Armed Forces of the Islamic Republic of Iran v Cubic Defense Systems, Inc. [1997] ICC 7365/FMS, Case No. 9994 [2001] ICC International Court of Arbitration; See Section 3.2 of N. M. Hằng and T. T. G. Thu, Proposing the Interpretation and Application of Article 420 Civil Code 2015 Regarding the Implementation of the Contract when the Circumstances Change Fundamentally [26/10/2017] Journal of International Economics and Management No.86.

[24] Law on Commercial Arbitration No. 54/2010/QH12 2010, Article 5.

[25] United Nations Convention on the Recognition and Enforcement of Foreign Arbitral Awards 1958, Article 1 and 3.

[26] See the Declaration of Vietnam on the Convention on the Recognition and Enforcement of Foreign
Arbitral Awards 1958: “... [The Socialist Republic of Viet Nam] Considers the Convention to be Applicable to the Recognition and Enforcement of Arbitral Awards Made Only in the Territory of Another Contracting State,..."

http://www.newyorkconvention.org/countries, (accessed on 24/06/2020).

[27] VINASME, "What Nudge" Can the Law Support Small and Medium Enterprises to Breakthrough and Develop?" VINASME (19/12/2019) http://vinasme.vn/Cu-huych-nao-de-Luat-Ho-trodoanh-nghiep-nho-va-vua-but-pha-phat-trien-175784.html (accessed on 27/08/2020); VINASME is the Official Forum of Small and Medium-size Companies in Viet Nam.

[28] Law on the Promulgation of Legal Documents of the National Assembly No. 17/2008/QH12 2008, Article 14.

[29] Code of Civil Procedure No. 92/2015/QH13 2015, Article 15.

[30] The Convention on the Recognition and Enforcement of Foreign Arbitral Awards 1958 Article 1, 2.; See [44-45].

[31] Decision on Implementation of Policies on Assistance for People Affected By COVID-19 Pandemic No. 15/2020/QD-TTg 2020. 